J. Clin. Chem. Clin. Biochem.

Vol. 27, 1989, pp. $191-195$

(C) 1989 Walter de Gruyter \& Co.

Berlin - New York

\title{
Observations on the Alkaline Haematin/Detergent Complex Proposed for Measuring Haemoglobin Concentration ${ }^{1}$ )
}

\author{
By O.W. van Assendelf $t^{2}$ )
}

Division of Host Factors, Center for Infectious Diseases, Centers for Disease Control, Public Health Service, U.S. Department of Health and Human Services, Atlanta, GA, U.S.A. and

\author{
W. G. Zijlstra ${ }^{2}$ )
}

Department of Physiology, University of Groningen, Groningen, the Netherlands

(Received June 29, 1987)

Summary: The "alkaline haematin D-575" method for determining haemoglobin, described by Zander et al. ((1984) Clin. Chim. Acta 136, 83-93) was tested. Claims that different non-ionic detergents in the reagent result in identical values for the haemoglobin concentration being measured could not be verified. It could also not be verified that a stable end-product with unique spectral characteristics is always reached within approximately $2 \mathrm{~min}$ and that conversion of fetal haemoglobin is faster than that with the haemiglobin cyanide method. Because of the many questions regarding the nature and characteristics of the alkaline haematin/detergent complex or complexes, it is not yet possible to recommend this method for routine haemoglobinometry.

\section{Introduction}

The International Committee for Standardization in Haematology (ICSH) recognizes three classes of methods $(1,2)$ : definitive, reference, and selected.

Definitive Method: a method which after exhaustive investigation is found to have no known source of inaccuracy or ambiguity as judged by a defined authority. It will, however, have a (known) degree of imprecision which should be stated.

Reference Method: a clearly and exactly described technique for a particular determination which, in the opinion of a defined authority, provides sufficiently accurate and precise laboratory data for it to be used to assess the validity of other laboratory methods for

\footnotetext{
1) The use of trade names is for identification only and does not constitute endorsement by the Public Health Service or the U.S. Department of Health and Human Services.

2) Dr. van Assendelft is chairman and Professor Dr. Zijlstra is a member of the ICSH Expert Panel on Haemoglobinometry.
}

this determination. The accuracy of the reference method must be established by comparison with a definitive method where one exists, and the degree of inaccuracy must be stated. The degree of imprecision must also be stated. An International Reference Method is one that has been established by a defined international authority.

Selected Method: a procedure the reliability of which has been validated by a collaborative study and which is recommended by a defined authority for routine use in a laboratory analysis, having been selected on the grounds of its accuracy and precision, the intended scope of the test, economy of labour and materials, and ease of operation. The degree of inaccuracy and imprecision must be stated.

The best-studied method in the clinical haematology laboratory is undoubtedly the spectrophotometric measurement of haemoglobin in human blood after conversion of haemoglobins to haemiglobin cyanide (HiCN; cyanmethaemoglobin). Review of the litera- 
ture, as well as results of extensive measurements, led the ICSH Expert Panel on Haemoglobinometry to formulate Recommendations for Haemoglobinometry in Human Blood in 1967 (3).

Every standardized method and all standards used must be continually critically evaluated and must not become static. If necessary, recommendations must be added to or eased, and new, proven techniques should be employed for preparation and checking of standards as they become available. This process is referred to as dynamic standardization. Accordingly, the Expert Panel on Haemoglobinometry has carefully monitored the literature on haemoglobinometry, organized symposia $(4,5)$, and revised the original recommendations in 1977 and $1987(6,7)$.

\section{The Reference Method}

The ICSH-recommended HiCN method was developed in the nineteen sixties after the redetermination of the (milli)molar absorptivity of $\mathrm{HiCN}$ at $540 \mathrm{~nm}$, $\varepsilon_{\mathrm{HiCN}}^{540}$, based on exhaustive haemoglobin-iron analyses $(8,9)$. The value measured has since been verified by various other methods, including $\mathrm{N}$ and $\mathrm{C}$ analyses, and X-ray emission spectrography (10). Statistical analysis of the published data allows us to state with confidence that $\varepsilon_{\mathrm{HiCN}}^{540}=10.99 \pm 0.011 \cdot \mathrm{mmol}^{-1}$. $\mathrm{cm}^{-1}$ (corresponding to $\left.1099 \pm 1 \mathrm{~m}^{2} \cdot \mathrm{mol}^{-1}\right)(\overline{\mathrm{x}} \pm$ standard error of the mean), $n=521$ (11). As the $\mathrm{HiCN}$ method has become increasingly used throughout the world, certain limitations have been described and accepted by the clinical laboratory community, e.g., loss of $\mathrm{CN}^{-}$from the reagent on storage, reagent instability on freezing, nonconversion of sulphaemoglobin to $\mathrm{HiCN}$, increased reaction time required to convert carboxyhaemoglobin, $\mathrm{HbCO}$, to $\mathrm{HiCN}(12-16)$. Review and revision of ICSH recommendations have taken these findings into account and include appropriate warnings in the description of the reference method. It is evident that the HiCN method meets the ICSH definition of a reference method: "a clearly and exactly described technique" with a stated degree of inaccuracy and imprecision.

\section{An Alternative Proposal}

In 1984, Zander, Lang \& Wolf described a method to measure haemoglobin photometrically after conversion to an alkaline haematin/detergent complex, which they called alkaline haematin D-575, abbreviated "AHD" (17). The authors describe their method as being "extremely stable," "rapid and accurate," "superior to the reference method" with the possibility of "direct standardization by a solid standard, stable in crystalline and dissolved form" that "can be handled easily for weighing" (18). The authors conclude that their method "meets the recommendations of the World Health Organization better than the conventional cyanhaemiglobin method" and question "which of the methods should be preferred in the future." Members of the ICSH Expert Panel on Haemoglobinometry, individually and collectively, have reviewed the method and have concluded that, although it has some merit, it cannot be considered a viable candidate for reference method status.

The reagent: Zander et al. report that "practically the same results are obtained when Triton X-100 concentration is varied between 10 and $50 \mathrm{~g} / 1$ or when $\mathrm{NaOH}$ concentration is varied between 0.01 and $1.0 \mathrm{~mol} / 1$, or when Triton $\mathrm{X}-100$ is replaced by other non-ionic detergents ..." This was tested by preparing three 0.1 $\mathrm{mol} / \mathrm{l} \mathrm{NaOH}$ solutions per litre containing $25 \mathrm{~g}$ Triton $\mathrm{X}-100,25 \mathrm{~g}$ Siponic 218 (PEG-10 isolauryl thioether), and $25 \mathrm{~g}$ Sterox SE (alkylphenol(thiol) polyethylene oxide), respectively. With these three reagents, the haemoglobin concentration of 11 normal blood specimens was determined and compared with that measured as $\mathrm{HiCN}(100 \mu \mathrm{l}$ sample plus $25 \mathrm{ml} \mathrm{HiCN}$ reagent). The Triton $\mathrm{X}-100$-containing reagent gave a mean difference of $+1.54 \mathrm{~g} / \mathrm{l}$ (range -2.7 to +4.7 $\mathrm{g} / \mathrm{l}$; standard deviation of the difference, $\mathrm{SD}_{\mathrm{d}}, 1.97$ $\mathrm{g} / \mathrm{l})$, the Siponic 218 -containing reagent a mean difference of $-0.6 \mathrm{~g} / 1$ (range -4.1 to $+2.2 \mathrm{~g} / \mathrm{l} ; \mathrm{SD}_{\mathrm{d}}$, $1.66 \mathrm{~g} / \mathrm{l})$, and the Sterox SE-containing reagent a mean difference of $-0.04 \mathrm{~g} / \mathrm{l}$ (range -3.5 to +2.1 $\left.\mathrm{g} / \mathrm{l} ; \mathrm{SD}_{\mathrm{d}}, 1.52 \mathrm{~g} / \mathrm{l}\right)$. All measurements were performed on a properly calibrated Varian Cary 219 spectrophotometer with appropriate blanks.

The end product, alkaline haematin/detergent complex: Zander et al. report that "alkaline haematin D-575" is characterized by a unique absorbance spectrum that is not influenced by the type of starting material (e. g., haematin, fresh human blood). Careful inspection of the authors' figure 2 (17), however, clearly shows differences, especially around $535 \mathrm{~nm}$ (absorbance minimum), between the end product obtained from freshly prepared haemin (chlorohaemin, a term used extensively in the German literature [19]), a year-old solution, and freshly drawn blood. We observed spectral changes of a blood/NaOH-Sterox SE mixture over a period of $48 \mathrm{~h}$, especially around the absorbance minimum $(535 \mathrm{~nm})$ and the shoulder around 600 $\mathrm{nm}$ (fig. 1), although the absorbance at $575 \mathrm{~nm}, \mathrm{~A}$ $575 \mathrm{~nm}$, changed little during that period.

Zander et al. report that the (milli)molar absorptivity at $575 \mathrm{~nm}$ of alkaline haematin D-575 was 6.960 $\pm 0.0461 \cdot \mathrm{mmol}^{-1} \cdot \mathrm{cm}^{-1}$ (corresponding to 696.0 


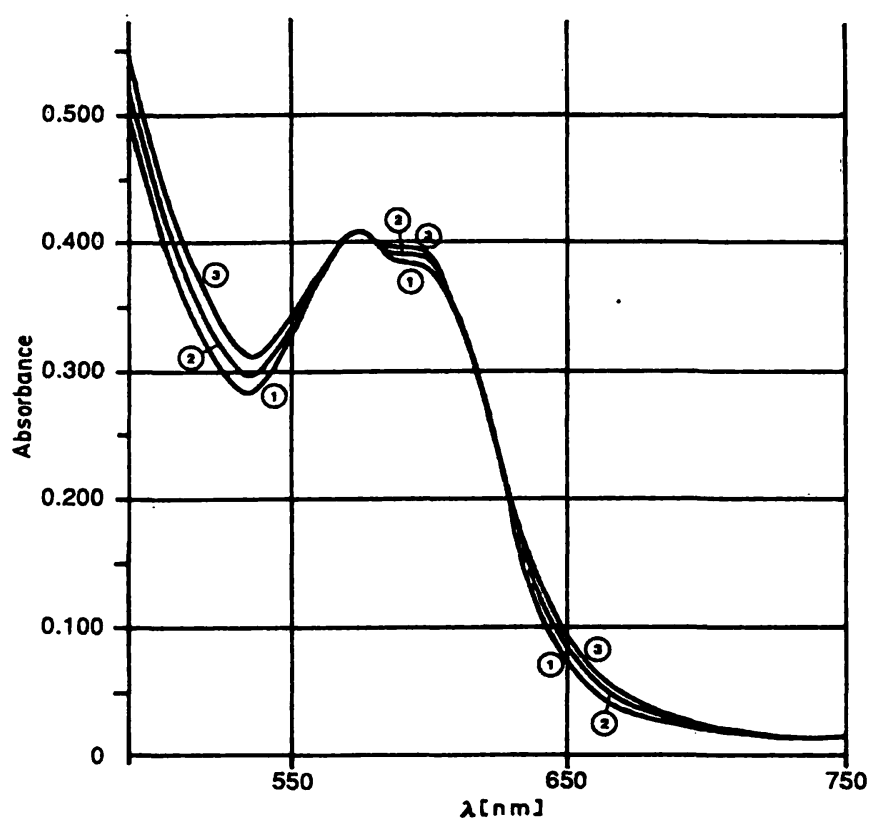

Fig. 1. Absorbance curves of $20 \mu \mathrm{l}$ fresh blood diluted with $3 \mathrm{ml}$ reagent containing $0.1 \mathrm{~mol} \mathrm{NaOH}$ and $25 \mathrm{~g}$ Sterox SE per liter. Curves recorded with a Varian Cary 219 spectrophotometer against the reagent blank $3 \mathrm{~h}$ after preparation (curve 1), $18 \mathrm{~h}$ after preparation (curve 2), and $48 \mathrm{~h}$ after preparation (curve 3 ).

$\left.\pm 4.6 \mathrm{~m}^{2} \cdot \mathrm{mol}^{-1}\right)(\mathrm{n}=24)$ when 12 haematin preparations were measured on two different days. When this value for $575 \mathrm{~nm}$ was used to calculate the haemoglobin concentration of blood samples, a systematic bias of $2.6 \%$ was found compared with results obtained with the HiCN method. The authors speculate that the cause of the bias could be that the
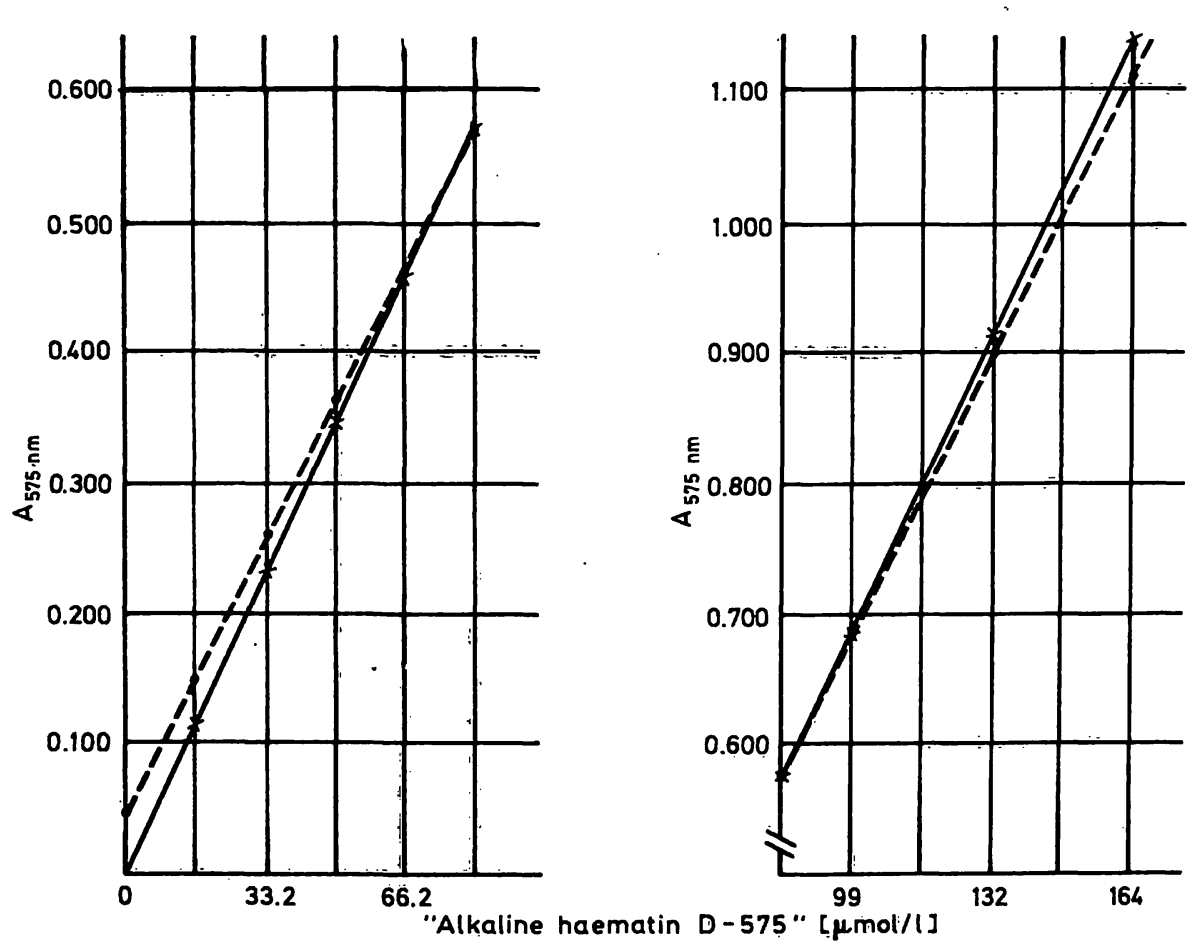

Fig. 2. Measured absorbance (dashed line) of "alkaline haematin D-575" dilutions of a $10 \mathrm{mmol} / \mathrm{l}$ haemin stock solution plus $3 \mathrm{ml} \mathrm{NaOH}=$ Triton X-100 reagent, compared with the calculated absorbance (solid line) based on $\varepsilon_{575 \mathrm{~nm}}=6.961 \cdot \mathrm{mmol}^{-1}$ $\cdot \mathrm{cm}^{-1}\left(=696 \mathrm{~m}^{2} \cdot \mathrm{mol}^{-1}\right)$. Data from table 2, 1.c. (18). accepted value for $\varepsilon_{\mathrm{HiCN}}^{540}$ of $11.01 \cdot \mathrm{mmol}^{-1} \cdot \mathrm{cm}^{-1}(=$ $\left.1100 \mathrm{~m}^{2} \cdot \mathrm{mol}^{-1}\right)$ is erroneous. However, it should be taken into consideration that:

(1) the value of $\varepsilon_{\mathrm{HiCN}}^{\mathrm{s} 0}$ has been determined over a period of nearly two decades by more than 10 independent investigators using equine and human whole blood, washed red cells, and purified haemoglobin solutions, with various iron analyses, including $\mathrm{X}$-ray emission spectrography, with $\mathrm{N}$ and $\mathrm{C}$ analyses, and with a titrimetric method (20), encompassing a total of 521 determinations $(10,11)$;

(2) the authors' value of $575 \mathrm{~nm}$ is based on 12 samples of one type of material (recrystallized haemin) for which they provide no data on purity as determined by independent chemical assays; and

(3) there is no guarantee that their corresponding haemoglobin determinations with the $\mathrm{HiCN}$ method were correct, as commercial reagents and standards were used (Boehringer, Merck) that in the past have given erroneous results (21).

Zander et al. claim that a "strong linear dependence" exists between the concentration of alkaline haematin D-575 and absorbance. Careful inspection of their data (1.c. (18), table 2) suggests, however, increasing alinearity with decreasing concentration below 6.6 $\times 10^{-2} \mathrm{mmol} / 1$ and some alinearity with increasing concentration above $8.2 \times 10^{-2} \mathrm{mmol} / 1$ (tab. 1 ; fig. 2). 
Tab. 1. Calculated (based on (milli)molar absorptivity $=6.961$ - $\left.\mathrm{mmol}^{-1} \cdot \mathrm{cm}^{-1}\left(=696 \mathrm{~m}^{2} \cdot \mathrm{mol}^{-1}\right)\right)$ and measured absorbance of "alkaline haematin D-575" solutions. Data from l.c. (18).

\begin{tabular}{llll}
\hline Haematin & \multicolumn{2}{l}{ Absorbance } & $\begin{array}{l}\text { Deviation from } \\
\text { calculated ab- } \\
\text { sorbance (\%) }\end{array}$ \\
\cline { 2 - 4 }$\left(10^{-2} \mathrm{mmol} / \mathrm{l}\right)^{*}$ & calculated & measured & +6.0 \\
1.66 & 0.116 & 0.123 & +2.2 \\
3.32 & 0.231 & 0.236 & +1.45 \\
4.975 & 0.346 & 0.351 & 0 \\
6.62 & 0.461 & 0.461 & 0 \\
8.26 & 0.575 & 0.575 & -1.45 \\
9.90 & 0.689 & 0.679 & -1.8 \\
13.16 & 0.916 & 0.899 & -2.2 \\
16.39 & 1.141 & 1.116 & \\
\hline
\end{tabular}

*) Multiply by 10 to obtain $\mu \mathrm{mol} / 1$

Method-related errors: Zander et al. stated in their first publication (17) that "all haemoglobin species with clinical significance converted into one single end product" and recently published a paper on plasma, cell ghost, leukocyte, and haemoglobin errors (22) in which they claim that the $\mathrm{HiCN}$ method overestimates the haemoglobin concentration of fetal haemoglobin (HbF)-containing blood by $0.4 \%$ to $0.7 \%$ when measuring 3 to $5 \mathrm{~min}$ after mixing blood and reagent. With the alkaline haematin/detergent method, the overestimation was reported to be no greater than $0.1 \%$. We studied the conversion time of $\mathrm{HbF}$ with three cord-blood specimens from premature infants, birth weight about 1200,1200 , and $800 \mathrm{~g}$. The HbF fraction, measured with an alkali denaturation method (23), was $0.65,0.77$, and 0.79 . The samples were diluted with $\mathrm{NaOH}-$ Triton X-100 (highly purified, Boehringer, cat. No. 789704) reagent and measured at $575 \mathrm{~nm}$ (bandpass $2 \mathrm{~nm}$ ) every $5 \mathrm{~s}$ for $10 \mathrm{~min}$ with an HP $8451 \mathrm{~A}$ diode array spectrophotometer calibrated as to wavelength and absorbance, with absence of stray light verified. The percent decrease in A 575 $\mathrm{nm}$ from $\mathrm{t}=5$ after initial mixing is summarized in table 2. Neither $\mathrm{HbF}$ nor normal $\mathrm{HbA}$ reached a stable value of A $575 \mathrm{~nm}$ during the 10 min that the reaction was followed. This may have been caused by insufficient "maturing" (18) of the reagent, which had been prepared only $24 \mathrm{~h}$ before use. After dilution with $\mathrm{HiCN}$ reagent, a stable A $540 \mathrm{~nm}$ reading was obtained after 3.5 and $4 \mathrm{~min}$ for sample $\mathrm{HbF} 3$ and $\mathrm{HbF} 1$ and 2, respectively.

\section{Conclusions}

Before any analytical system is implemented in a clinical laboratory, it must be validated by that laboratory, i.e., the laboratory must determine to its satisfaction that the system provides results as good or better than those given by the method already in routine use. Before any analytical system can acquire the status of selected or reference method, it must have been validated by one or more cooperative studies and be recommended by a defined authority. At least one attempt at validation of the "AHD" method has not yet been successful and has raised a number of questions, including:

1. What is the exact nature of the alkaline haematin/ detergent complex? Is the same complex obtained when different starting materials are used, e.g., haemin, haematin, purified haemoglobin solutions, washed erythrocytes, fresh whole blood, and when different non-ionic detergents are used? What is the true (milli)molar absorptivity of the complex or complexes?

2. Can freshly prepared hydroxide/detergent reagents be used, or do they have to "mature"? If so, what is the nature of the "maturation" process?

3. What results are obtained when the alkaline haematin/detergent method is compared with the HiCN reference method in a number of independent laboratories using $\mathrm{HiCN}$ standards and reagents of ICSH-recommended purity and composition?

With satisfactory answers to these questions, the alkaline haematin/detergent method could become an ICSH "selected method" or, as an extensive database on the method becomes available, a candidate for reference method. However, for a new method to replace an existing one as reference, distinct advantages and more than marginal improvement must be demonstrated. Because of the vast experience with the HiCN method, the large body of experimental work comprising every detail of the procedure, the wellfunctioning network of laboratories monitoring the International Reference Standards on the one hand

Tab. 2. Percent decrease from initial value of A $575 \mathrm{~nm}$ with time when cord blood specimens were mixed with $\mathrm{NaOH} / \mathrm{Triton}$ $\mathrm{X}-100$ reagent.

\begin{tabular}{llllllrrrrrr}
\hline $\begin{array}{l}\text { Time (s) } \\
\text { Sample }\end{array}$ & 5 & 60 & 120 & 180 & 240 & 300 & 360 & 420 & 480 & 540 & 600 \\
\hline HbF 1. & 0 & 3.2 & 5.3 & 6.9 & 8.1 & 9.6 & 12.3 & 11.2 & 12.9 & $\ddots 14.1$ & 15.3 \\
2 & 0 & 2.6 & 5.1 & 7.5 & 7.7 & 8.5 & 9.4 & 10.4 & 11.2 & 12.1 & 12.8 \\
3 & 0 & 3.3 & 5.7 & 7.4 & 8.8 & 10.3 & 11.7 & 12.4 & 13.4 & 14.6 & 15.5 \\
HbA (normal) & 0 & 1.4 & 2.4 & 2.9 & 3.4 & 3.9 & 6.1 & 6.0 & 5.6 & 6.7 & 7.5 \\
\hline
\end{tabular}


and the great effort and long time necessary to achieve worldwide standardization of any clinical laboratory procedure on the other, extreme care should be taken and very clear advantages should be within reach before the current reference system for haemoglobinometry can be challenged.

Reported advantages of the "AHD" method are the smaller influence of turbidity by plasma components and erythrocyte ghosts, obviously the result of the more alkaline reagent solution, and the shorter conversion time, especially with carboxyhaemoglobin. Except with such a degree of hyperlipaemia detectable by even an average laboratory technician, the im- provements obtained are only marginal. The authors (22) have measured a "normal plasma error," expressed as absorbance, of 0.005 for the HiCN method, compared with 0.003 for the "AHD" method but fail to provide data on the probable traces of plasma haemoglobin in the 14 samples studied. The improvement gained with respect to an erythrocyte ghost error is less than marginal: 0.0015 with the $\mathrm{HiCN}$ method compared with 0.0010 with the "AHD" method; number of samples studied is not given. Finally, a carboxyhaemoglobin error in the $\mathrm{HiCN}$ method will only become clinically significant when the fraction of carboxyhaemoglobin is high enough to cause clear clinical signs of carbon monoxide poisoning (12).

\section{References}

1. International Committee for Standardization in Haematology, Rules and Operating Procedures, 1986.

2. van Assendelft, O. W. \& England, J. M. (1982) In: Advances in Hematological Methods: the Blood Count (van Assendelf,, O. W. \& England, J. M., eds.) pp. 1-9, CRC Press, Boca Raton, FL.

3. International Committee for Standardization in Haematology (1967) Br. J. Haematol. 13, Suppl., 71-75.

4. Astaldi, G., Sirtori, C. \& Vanzetti, G., eds. (1970) Standardization in Hematology, 13-72, 73-120, 254-305, Fondazione Carlo Erba, Milan.

5. Izak, G. \& Lewis, S. M., eds. (1972) Modern Concepts in Hematology, pp. 11-68, Academic Press, New York.

6. International Committee for Standardization in Haematology (1978) J. Clin. Pathol. 31, 139-143.

7. International Committee for Standardization in Haematology (1987) Clin. Lab. Haemat. 9, 73-79.

8. Zijlstra, W. G. \& van Kampen, E. J. (1960) Clin. Chim. Acta $5,719-726$.

9. van Kampen, E. J. \& Zijlstra, W. G. (1961) Clin. Chim. Acta 6, 538-544.

10. van Kampen, E. J. \& Zijlstra, W. G. (1983) Adv. Clin. Chem. 23, 199-257.

11. van Assendelft, O. W. (1979) In: Handbook Series in Clinical Laboratory Science, Section I: Hematology, Vol. I (Schmidt, R. M., ed.) pp. 211-220, CRC Press, Boca Raton, FL.

12. van Assendelft, O. W., Zijlstra, W. G. \& van Kampen, E. J. (1970) Proc. Kon. Ned. Akad. Wet. Ser. C 73, 104-112.

13. Weatherburn, M. V. \& Logan, J. E. (1964) Clin. Chim. Acta 9, $581-584$.

14. Zweens, J., Frankena, H. \& Zijlstra, W. G. (1979) Clin. Chim. Acta 91, 337-352.

15. Dijkhuizen, P., Buursma, A., Gerding, A. M. \& Zijlstra, W. G. (1977) Clin. Chim. Acta 78, 479-487.

16. Taylor, J. D. \& Miller, J. D. M. (1965) Am. J. Clin. Pathol. $43,265-271$.

17. Zander, R., Lang, W. \& Wolf, H. U. (1984) Clin. Chim. Acta 136, 83-93.

18. Wolf, H. U., Lang, W. \& Zander, R. (1984) Clin. Chim. Acta $136,95-104$.

19. Falk, J. E. (1964) Porphyrins and Metalloporphyrins, pp. 16-17, Elsevier Publishing Company, Amsterdam.

20. Hoek, W., Kamphuis, N. \& Gast, R. (1981) J. Clin. Chem. Clin. Biochem. 19, 1209-1210.

21. van Assendelft, O. W., Koedam, J. C. \& Terlingen, J. B. (1982) In: Advances in Hematological Methods: The Blood Count (van Assendelft, O. W. \& England, J. M., eds.) pp. 195-205, CRC Press, Boca Raton, FL.

22. Zander, R., Lang, W. \& Wolf, H. U. (1989) J. Clin. Chem Clin. Biochem. 27, 185-189.

23. National Committee for Clinical Laboratory Standards (1986) H13-T, Quantitative Measurement of Fetal Hemoglobin by the Alkali Denaturation Method, NCCLS, Villanova, PA.

Dr. O. W. van Assendelft

Chief, Clinical Medicine Branch

Division of Host Factors

Center for Infectious Diseases

Centers for Disease Control

Bldg. 1, Rm. 1407

Atlanta GA 30333 U.S. A. 
